\title{
THE FUNCTIONAL ORGANIZATION \\ OF RESPIRATORY NEURONES: A REVIEW
}

\author{
J. Duffrn, PH.D.*
}

ALthough ReVIEWERS SUCH AS Robson, ${ }^{1}$ Wang and Ngai, ${ }^{2}$ Salmoiraghi, ${ }^{3}$ Oberholzer and Tofani, ${ }^{4}$ Liljestrand, ${ }^{5}$ Wang et al., ${ }^{6}$ Hoff and Breckenridge, ${ }^{7}$ Wyss, ${ }^{8}$ Pitts, ${ }^{2}$ and Cordier and Heymans ${ }^{10}$ provide a detailed history of respiratory neurophysiology, it is pertinent to outline the development of theories about the central organization of respiratory neurones in order to understand current experimental work, and to aid in the synthesis of a comprehensive model of the functional organization of respiratory neurones.

The early techniques of transection of the brain and ablation of specific parts of the brain were used to relate function and structure. In this way, the location of the essential neuronal mechanism governing rhythmic respiration was found to lie between the first cervical segment of the spinal cord and the highest point of vagal entry into the brainstem. Further transection of the pons and medulla caused marked changes in respiration. Marckwald ${ }^{11,12}$ proposed that eupnoea results from reciprocal innervation between inspiratory and expiratory groups of neurones. The inspiratory centre in the medulla was inhibited by the expiratory centre also in the medulla, which in turn was excited periodically by the pneumotaxic centre located in the pons. Lumsden ${ }^{15-10}$ confirmed Marckwald's view and proposed, in addition, an apneustic centre with the function of tonically stimulating the inspiratory centre. Pitts et al. ${ }^{17,18}$ studied the interrelations of the postulated centres, and established the functional importance of the vagus nerves in the maintenance of rhythmicity. He reviewed ${ }^{9}$ previous experimental work and proposed an acceptable theory of respiratory rhythmicity and organization which has been consolidated by the stimulation, transection and ablation experiments of Tang, ${ }^{19}$ Liljestrand, ${ }^{20}$ Baxter and Olszewski, ${ }^{21}$ Wang et al., ${ }^{6}$ and Ngai and Wang ${ }^{22}$ which are reviewed by Wang and Ngai ${ }^{2}$

Briefly, the organization of respiratory neurones and their interconnections, which produces rhythmic respiration was thought to be the following. Two medullary populations of respiratory neurones make up the inspiratory and expiratory centres and are mutually inhibiting. They are acted upon by the pontine centres. A tonically active apneustic centre continually excites the inspiratory centre, while a periodically active pneumotaxic centre together with vagal afferents excites the expiratory centre. Rhythm in this system is brought about by the periodic excitation of expiratory neurones by the vagal afferents and pneumotaxic centre. The system is monostable, resting in an inspiratory position if isolated.

This theory accounted for the observation that vagotomized, mid-pontile decerebrate animals exhibited sustained inspiratory activity or apneusis. Section of

-Department of Anaesthesia, Faculty of Medicine, University of Toronto. 
the pons so as to isolate the upper pontine pneumotaxic centre from the medullary expiratory centre, together with vagotomy, will leave only the inspiratory centre, facilitated by the apeneustic centre in the lower pons.

The findings of Hoff and Breckenridge, ${ }^{23,24}$ that animals sectioned between pons and medulla exhibit rhythmic respiration rather than apneusis, cast doubt upon the above explanation of apneusis. Hoff and Breckenridge concluded that apneusis was a part of decerebrate rigidity in which the respiratory muscles joined. Breckenridge et al ${ }^{25}$ attempted to prove their theory by chemically abolishing decerebrate rigidity and simultaneously abolishing apneusis, but Wang et al. ${ }^{6}$ disputed their conclusion that the two events are linked.

Nevertheless, the importance of the pontine centres, and the tonicity of the inspiratory centre had been questioned. The introduction of the micro-electrode, capable of measuring intracellular and extracellular potentials from single respiratory neurones, allowed detailed study of the organization of central respiratory neurones. In a series of papers, Burns and Salmoiraghi ${ }^{26-28}$ localized a respiratory area of mixed inspiratory and expiratory neurones in the lateral reticular formation of the medulla oblongata, about the level of the obex, in cats. They did not find the respiratory neurones in the pons recorded by Takagi and Nakayama ${ }^{29}$ and Cohen and Wang. ${ }^{30}$

These microelectrode studies of Burns and Salmoiraghi led to a theory of respiratory rhythmicity in which there were only two types of respiratory neurones, the inspiratory and expiratory populations, and neither population was tonically active. Contrary to the earlier theory, the pons was not considered essential and the inspiratory neurones were not assumed to be tonically active. The two populations of neurones were thought to be mutually inhibiting, so that they formed a bi-stable system, capable of resting in either an inspiratory or an expiratory position. Each population was thought to be connected in the form of self reexciting chains so as to maintain its burst of action potentials, a deduction supported by the fact that individual neurones exhibit randomness during each burst and the fact that the activity of the whole population could be arrested by an electric shock in a process analogous to heart defibrillation. The activity in each population was thought to be ended both by the growth of excitement in the other inhibiting population and by a general decrease in individual excitability. ${ }^{31}$ The bi-stable system was powered by the general neuronal traffic of the medulla, since rhythmicity was not detectable in isolated medullary slabs.

In contrast to the mono-stable system in which respiration may be arrested only in the inspiratory phase, the bi-stable system may become arrested in either phase. Robson et al. ${ }^{32}$ demonstrated, by means of microelectrode recordings of cat respiratory neurones, that high doses of barbiturates caused continuous firing of the inspiratory population, which could be switched over to continuous firing of expiratory neurones by either inflation of the lungs or a non-specific stimulus such as a sciatic nerve shock. Similar effects were observed for other anaesthetics and hyperventilation. These observations supported the theory of the bi-stable system, reviewed by Salmoiraghi ${ }^{3}$ and Robson. ${ }^{1}$

In the theory of the bi-stable system, the effects of pontine neurones are not thought to be essential to the generation of rhythmic respiration but as assisting 
the smooth transition from one phase of respiration to the other. Kahn and Wang ${ }^{33}$ however, have re-emphasized the importance of the pons in the neuronal regulation of ventilation. They recorded phrenic nerve discharge in 25 paralysed, midcollicular decerebrate cats whose respiration was maintained by a respirator providing sustained inflation and deflation. In one group of cats they found little change in phrenic discharge after bilateral vagotomy, but in another group they found that pre-trigeminal midpontine transection abolished the gradual increase and abrupt termination of the phrenic discharge observed in normal cats. Kahn and Wang concluded that the pneumotaxic centre in the rostral pons was important in the generation of eupnoea.

Kahn and Wang ${ }^{34}$ also re-examined the phenomenon of apneusis. They found that in paralysed, mid-pontile decerebrate cats, a physiological denervation of the vagus by sustained lung deflation could produce an apneustic pattem of phrenic discharge. Kahn and Wang also studied respiratory neurones before and after bilateral vagotomy in midpontile decerebrate cats. They found that 4 medullary and 2 of 4 pontine inspiratory neurones discharged synchronously with the apneustic pattem of phrenic discharge after vagotomy. Kahn and Wang concluded that apneusis is a specific respiratory function, and that they had demonstrated inspiratory neurones in the nuclei reticularis and magnocellularis region of the pons whose behaviour was consistent with their being part of a functional apneustic centre. They also concluded that the Hering-Breuer reflex is integrated in the pons since medullary cats exhibited no Hering-Breuer reflexes.

Microelectrode examination of respiratory neurones has revealed many different discharge patterns and reactions to changing stimuli. ${ }^{35}$ Batsel ${ }^{36}$ examined the effects of hyperventilation on the firing patterns of respiratory neurones of cats, in the regions of the nucleus ambiguous, both caudal and rostral to the obex. Some cats were anaesthetized with pentobarbital or urethane, while others were decerebrate at the midcollicular level; most were vagotomized. He found that the majority of inspiratory neurones examined were inactivated by hyperventilation, with those firing late in the inspiratory phase affected first. Some inspiratory units progressed into tonic discharge, the majority being those firing early in the inspiratory phase. Most expiratory neurones observed went into tonic discharge during hyperventilation. These units were predominantly those which began discharging early in the expiratory phase. The remaining expiratory neurones examined, mostly the type which began firing late in expiration, were found to be progressively inactivated by hyperventilation.

Cohen ${ }^{37-88}$ observed both pontine and medullary respiratory neurones of cats during lung inflation, hypocapnia and hypercapnia. The preparations were either anaesthetized, (urethane or dialurethane) or midcollicular decerebate. Phrenic nerve discharge was monitored to determine the phase of respiration. Only the cats studied during lung inflation were not vagotomized. Cohen ${ }^{39}$ summarized his results, and classified the observed neurones with respect to their time relation to the phrenic discharge. Neurones firing only during either phase were inspiratory or expiratory, with late and early firing types included. Neurones whose discharge spanned the respiratory phase were inspiratory-expiratory or expiratory-inspiratory according to the phase in which they began firing. Phase-spanning neurones were 
mostly found in the pons. Cohen's findings for hypocapnia agreed with Batsel's; the neurones examined which became quiescent were mostly inspiratory, early and late expiratory and inspiratory-expiratory types, while those that became tonically active were mostly expiratory-inspiratory neurones. The expiratory units observed were found to fall equally into tonic or quiescent categories. In Cohen's lung inflation studies most neurones examined performed as expected, in that inspiratory neurones were depressed and expiratory neurones were excited, but some appeared to contradict the expected performance. These were presumed to be interneurones in the vagal reflex pathway.

Cohen accounts for his observations by adopting a model of the neuronal regulation of ventilation where the central inspiratory, expiratory oscillator is acted upon by several subsidiary control loops. Inspiration is initiated by expiratoryinspiratory neurones which are then inhibited by the inspiratory neurones, early expiratory neurones and vagal afferents. Inspiration is terminated by inhibition due to interneurones excited by the vagal afferents and the inspiratory population themselves. Expiration is terminated by expiratory inhibitory neurones activated by vagal afferents and the expiratory units themselves.

Salmoiraghi and Burns, ${ }^{3}$ however, have described how different types of firing pattern may result, and if account is taken of the role of the pontine respiratory neurones, then the cycling of respiratory neurones may be described as the following sequence of events.

During the period before inspiration and after expiration some highly facilitated units of either population are firing continuously due to stimulation by general neuronal trafic. Chemoreceptive excitation of such highly facilitated, pontine inspiratory neurones gives the inspiratory neurones a majority, and is enough to start an avalanche of excitation spreading through the less facilitated inspiratory units; the expiratory neurones are inhibited by the inspiratory discharge. Phrenic discharge and lung inflation builds up slowly, beginning as the medullary units start. Meanwhile, many pontine inspiratory units have stopped firing because of a rise in their threshold caused by their rapid firing rate. The decreased inhibition and increased vagal afferent excitation gives the highly facilitated, pontine expiratory neurones a majority, and an avalanche of excitation spreads through the expiratory population cutting off the already declining inspiratory discharge, and in this way abruptly terminating the phrenic discharge. The expiratory wave of excitation climbs to as high a threshold neurone as it can, given the initial impetus; and then falls as the level of excitability declines due to rapid firing.

Such a model explains the more recent categorizations of neurones, not as a highly complex system of functions but as either expiratory or inspiratory neurones whose facilitation may vary from high to low depending upon their excitatory and inhibitory connections. Phase spanning neurones are, therefore, the highly facilitated units whose discharge leads that of the phrenic nerve, which is itself presumed to be activated by less facilitated units. The respiratory centres are locations in which there is a preponderance of one type of neurone. For example, the pneumotaxic centre may be a region of highly facilitated (low threshold) expiratory neurones, and the apneustic centre may be a locale of highly facilitated inspiratory neurones. The persistence of tonic inspiratory and expiratory units during hypo- 
capnia merely indicates the presence of a highly facilitated nẹurone, no longer rhythmically inhibited by its opposite.

\section{SUMMARY}

The classical work reviewed by Pitts and consolidated by stimulation, transection and ablation experiments reviewed by Wang and Ngai, ${ }^{2}$ revealed a subdivision of medullary respiratory neurones into mutually inhibiting inspiratory and expiratory centres. Pontine, apneustic and pneumotaxic centres were thought to excite the inspiratory and expiratory centres respectively. The apneustic centre was presumed to be tonically active while the pneumotaxic centre was periodically active and generated respiratory rhythmicity with the aid of vagal afferents.

Microelectrode techniques used to examine individual neurones by Burns and Salmoiraghi ${ }^{20-28}$ and reviewed by Salmoiraghi, ${ }^{3}$ have led to a new theory of respiratory neuronal organization. As previously, mutually inhibitory populations of inspiratory and expiratory neurones form the basic medullary oscillator. These neurones are not located in centres but intermingled and apparently connected in self re-exciting chains. The oscillator is driven by chemoreceptor and lung afferents and also by the general medullary traffic. Pontine functions are not thought to be essential to its operation but as aiding the smooth transition from one respiratory phase to the next.

Further microelectrode studies ${ }^{36-i 8}$ have indicated the complexity of behaviour of respiratory neurones, and re-emphasized the importance of pontine neurones. $\mathrm{Cohen}^{\text {3a }}$ has proposed a model of the functional organization of respiratory neurones which employs several subsidiary control loops acting upon the main oscillator, in order to account for these findings. It is argued, however, that the complex behaviour of individual respiratory neurones may be due to their varying degrees of excitation from the medullary environment, so that the model of Salmoiraghi and Burns is still appropriate.

\section{RÉsumé}

Le travail classique revu par Pitts et consolidé par des expériences revisées par Wang et Ngai, expériences de stimilation, transection et ablation, révèle une subdivision des neurones médullaires respiratoires en des centres inhibiteurs mutuels inspiratoires et expiratoires. Les centres pontin, apneustique et pneumotaxique sont des excitateurs, pense-t-on, des centres inspiratoire et expiratoire respectivement. On présume que le centre apneustique serait tonique et actif alors que le centre pneumotaxique serait par périodes actif et serait à l'origine de la rhythmicité avec l'aide de fibres vagales afférentes.

Les techniques de microélectrodes utilisées pour étudier chaque neurone par Burns et Salmoiraghi ${ }^{26-28}$ et revisées par Salmoiraghi, " ont contribué à élaborer une nouvelle théorie sur l'organisation neuronale respiratoire. Tel qu'auparavant, un groupe de neurones inspiratoires et expiratoires s'inhibant mutuellement constitue l'oscillateur médullaire de base.

Ces neurones ne sont pas situés dans les centres mais entremêlés et apparem- 
ment reliés à des chaines engendrant de nouvelles excitations. L'oscillateur est activé par le chémorécepteur et les bronches afférentes du poumon et aussi par l'ensemble des influx médullaires. Les fonctions du pont ne sont essentielles à son activité, croit-on, mais aideraient au changement doux d'une phase respiratoire à l'autre.

D'autres études ${ }^{30-38}$ avec des microélectrodes ont indiqué la complexité d'action des neurones respiratoires et soulignent limportance des neurones pontins. Cohen ${ }^{g a}$ a proposé un modèle de Porganisation fonctionnelle des neurones respiratoires qui utilise de nombreuses boucles subsidiaires de controle qui agissent sur l'oscillateur principal de façon à tenir compte de ces découvertes. Toutefois, on prétend que la conduite complexe des neurones respiratoires individuels pourtait être attribuable à leurs degrés variables d'excitation du voisinage médullaire, de sorte que le modèle de Salmoiraghi et Burns encore à point.

\section{REFERENCES}

1. Robson, J. G. The Mespiratory Centres and Their Responses. In: Modem Trends in Anaesthesia 3, edited by F. T. Evans and T. C. Gray, London, Butterworths (1967).

2. WANG, S. C. \& NGAI, S. H. General Organization of Central Respiratory Mechanisms. In: Handbook of Physiology, section 3, volume 1, edited by W. O. Fenn and H. Rahn. Washington, oc, American Physiological Society (1964).

3. Salmorragir, G. C. Functional Organization of Brain Stem Respiratory Neurons. Ann. Now York Acad. Sct., 109: 571 ( 1963 )

4. Oneluolzen, R. J. H. \& Torani, W. O. The Neural Control of Respiration, In: Hand. book of Physiology, Section 1: Neurophysiology Vol. $\mathrm{m}$, edited by J. Field and $\mathrm{H}$. W. Magoun, Washington DC, American Physiology Society (1960).

5. Lirjestrand, A. Neural Control of Respiration. Physiol. Rev., 38: 691 (1958).

6. Wang, S. C., Nani, S, H., \& Frumin, M. J. Organization of Central Respiratory Mechanisms in the Brain Stem of the Cat: Genesis of Normal Respiratory Rhythmicity. Am. J. Physiol., 190: 333 (1957).

7. HoFf, H. E. \& Breckenfadre, C. G. The Neurogenesis of Respiration. In: A Textbook of Physiology, 17th Edition, edited by J. F. Fulton, Philadelphia, W. B. Saunders Co (1955).

8. Wrss, O. A. M. Respiratory Centre and Reflex Control of Breathing. Helvet physiol. et pharmacol. acta, 12 (Suppl. 10): 4 (1954).

9. Prtrs, R. F. Organization of the Respiratory Centre. Physiol. Hev., 26:609 (1946).

10. Conpier, D. Heymans, C. Le Centre Respiratoire. Ann, Physiol, Physiochim. biol. 11 : $535(1935)$.

11. Manckwald, M. The Movements of Hespiration, translated by T. A. Haig, London, Blackie and Son (1883)

12. Marckwald, M. Die Athembewegunden und deren Innervation beim Kaninchem. Z. Biol., 23: (1887)

13. Lumsden, T. Observations on the Respiratory Centres in the Cat. J. Physiol., 57: 153 (1923).

14. Lumsden, T. Observations on the Respiratory Centres. J. Physiol, 57: 354 (1923).

15. Lumsden, T. The Regulation of Respiration. Part I. J. Physiol, 58: 81 (1923).

16. Lomsden, T. The Regulation of Respiration. Part II. J. Physiol., 58: 111 (1923)

17. PITTs, R. F. Organization of the Respiratory Centre. Physiol. Rev., 26: 609 (1946).

18. Prits, R. F., Macoun, H. W. \& Ransom, S. W. The Origin of Respiratory Rhythmicity. Am, J. Physiol., 127: 654 (1939).

19. Tang, P. C. Localization of the Pneumotaxic Centre in the Cat. Am. J. Physiol, 172: $645(1953)$.

20. Lif Jestrund, A. Respiratory Reactions Elicited from Medulla Oblongata of the Cat. Acta. physiol. scandinav. 29 (Suppl. 106); 321 ( 1953).

21. BAxter, D. W. \& Otszewski, J. Respiratory Responses Evoked by Electrical Stimulation of Pons and Mesencephalon. J. Neurophysiol., 18: 276 (1955).

22. NGar, S. H. \& WANG, S. C. Organization of Central Respiratory Mechanisms in the 
Brain Stem of the Cat: Localization by Stimulation and Destruction. Am. J. Physiol., 190: 343 (1957).

23. Hoff, H. E. \& Breckennadge, C. G. The Medullary Origin of Respiratory Periodicity in the Dog. Am. J. Physiol., 158: 157 (1949).

24. Breckenrmge, C. G., Horf, H. E., \& Smrrr, H. T. Pontine and Medullary Regulation of Respiration in the Cat. Am. J. Physiol., 160: 385 (1950).

25. Bheckenrmat, C. G., Hoff, H. E., \& SMrte, H. T. Effect on Respiration in Midpontile Animal of Chemical Inbibition of Facilitatory System. Am. J. Physiol., 162: 74 (1950).

26. BunNs, B. D. SAlmoinaght, C. C. Repetitive Firing of Respiratory Neurones During Their Burst Activity. J. Neurophystol., 23: 27 (1960).

27. Salmomach, G. C. \& Burns, B. D. Localization and Patterns of Discharge of Respiratory Neurons in Brain-Stem of Cat. J. Neurophysiol, $29: 2$ (1960).

28. Salmotrachr, G. C. B Bunss, B. D. Notes on Mechanism of Rhythmic Respiration. J. Neurophysiol, 23: 14 (1960).

29. Takagr, K, N Naxayama, T. Respiratory Discharge of the Pons. Science, 128: 1206 (1958).

30. Cohren, M. I. \& WANG, S. C. Respiratory Neuronal Activity in Pons of Cat. J. Neurophysiol, $22: 33$ (1959).

31. Salmolrach, G. C. \& von Baumganten, R. Intracellular Potentials from Respiratory Neurons in the Brainstem of the Cat and the Mechanism of Rhythmic Respiration. I. Neurophysiol., 23: 2(1961).

32. Robson, J. G., Hoosezey, M. A. \& Solis-Quinoga, O. H. The Mechanism of Respiratory Arrest with Sodium Pentobarbital and Sodium Thiopental. Ann. New York Acad. se., 109; 494 (1963).

33. Kakn, N. \& Wang, S. C. Pontine Pneumotaxic Centre and Central Respiratory Rhythm. Am. J. Physiol., 211: 520 (1966).

34. KaHN, N. \& WANG, S. C. Electrophysiologic Basis for Pontine Apneustic Centre and its Role in Integration of the Hering-Brever Reflex. J. Neurophysiol, 30: 301 (1967).

35. Nestand, R. \& PuvM, F. Subtypes of Medullary Respiratory Neurons. Exptl. Neurol, 12: 337 (1965).

36. Batsel, H. L. The Activity of Bulbar Respiratory Neurons during Passive Hyperventilation. Exptl. Neurol., 19: 357 (1967).

37. Comen, M. I. Discharge Patterns of Brain Stem Respiratory Neurons in Relation to $\mathbf{C O}_{2}$ Tension. J. Neurophysiol., 31 : 142 (1968).

38. Conen, M. I. Discharge Patterns of Brainstem Respiratory Neurons during HeringBreuer Reflex Evoked by Lung Inflation. J. Neurophysiol, 32: 356 (1969).

39. ConwN, M. I. How Respiratory Rhythm Otiginates: Evidence from Discharge Patterns of Brainstem Respiratory Neurons. In: Breathing: Hering.Breuer Centenary Symposium, edited by R. Porter, London, Churchill (1970). 